\title{
The occurrence and preference of Botanophila flies (Diptera: Anthomyiidae) for particular species of Epichlö fungi infecting wild grasses
}

\author{
Marlena LEMBICZ ${ }^{1}$, Karolina GÓRZYŃSKA ${ }^{1}$, ZIEMOWIT OLSZANOWSKI $^{2}$, Verner MICHELSEN ${ }^{3}$ \\ and ADRIAN LEUCHTMANN ${ }^{4}$ \\ ${ }^{1}$ Department of Plant Taxonomy, A. Mickiewicz University, Umultowska 89, 61-614 Poznań, Poland; \\ e-mails: lembicz@amu.edu.pl; karjan@amu.edu.pl \\ ${ }^{2}$ Department of Animal Taxonomy and Ecology, A. Mickiewicz University, Umultowska 89, 61-614 Poznań, Poland; \\ e-mail: olszanow@amu.edu.pl \\ ${ }^{3}$ Zoological Museum, Universitetsparken 15, DK-2100 Copenhagen Ø, Denmark; e-mail: vmichelsen@snm.ku.dk \\ ${ }^{4}$ ETH Zürich, Plant Ecological Genetics, Institute of Integrative Biology (IBZ), Universitätstrasse 16, 8092 Zürich, Switzerland; \\ e-mail: adrian.leuchtmann@env.ethz.ch
}

Key words. Diptera, Anthomyiidae, Botanophila, egg morphology, fungi, Clavicipitaceae, Epichloë, molecular phylogeny, Poland

\begin{abstract}
Specific associations between species frequently occur in ecological interactions. The aim of this study was to determine the preferences of anthomyiid flies of the genus Botanophila for particular species of fungi as sites for laying eggs and as food for both larvae and adults. The associations of their eggs, larvae and flies with the stromata of different species of Epichloë fungi infecting 7 species of grass in Poland were analyzed. Scanning electron microscopy of the surface of their eggs and an analysis of the genetic sequences of their mitochondrial cytochrome oxidase (COII) were used to identify the taxa of the flies studied. Three types of eggs were distinguished based on their shape, colour and the presence of dorsal folds and sculpturing on the shells. Tentatively, these eggs were assigned to the following species: $B$. laterella, B. phrenione, B. dissecta and B. lobata. COII sequences obtained from larvae that hatched from two of the types of eggs formed three distinct clades associated with the reference sequences for Botanophila phrenione, B. lobata (new to the fauna of Poland) and a putative species, "Taxon 1". Only one of these flies (B. lobata) was restricted to a single species of Epichlö̈ (E. bromicola on Elymus repens); B. phrenione was recorded mainly from E. typhina infecting three different species of grass. The results of this study confirm that there is not a close species specific association between this fungus and this insect.
\end{abstract}

\section{INTRODUCTION}

The genus Botanophila currently includes approximately 70 species (Michelsen, 2011). Initially, only one of these species, B. phrenione (Séguy) [earlier described as Anthomyia spreta Meigen and Phorbia phrenione (Séguy)] was thought to be associated with Epichlö fungi (Kohlmeyer, 1956; Williams, 1971). At present, the relationship with Epichlö fungi is more or less confirmed for 6 European species of Botanophila [in addition to $B$. phrenione, these species include $B$. dissecta (Meigen), B. laterella (Collin), B. latifrons (Zetterstedt), B. lobata (Collin) and B. cuspidata (Collin)] (Collin, 1967; Ackland, 1972; Hennig, 1976). More recently the mitochondrial gene of subunit 2 of cytochrome oxidase (COII) of species of the genus Botanophila collected from different species of fungus in Switzerland, Poland and the USA was sequenced. These studies revealed that at least six distinct Botanophila taxa are associated with Epichloë fungi (Leuchtmann, 2007).

Flies of the genus Botanophila in transferring spermatia between different mating types of heterothallic fungi behave like pollen-transferring insects (Bultman, 1995). In both cases, this process results in the fertilisation and production of dispersal structures. In Epichloë, these structures are meiotic ascospores, capable of infecting other plants (Chung \& Schardl, 1997; Brem \& Leuchtmann, 1999). Despite recent intensive research, the degree of specificity or preference shown by Botanophila for particular species of the fungus Epichloë has been little studied and the results ambiguous. Studies are needed to determine whether the associations are mutualistic, parasitic or neutral for one or both partners and whether it is a consequence of coevolution. Recently, new information has emerged that indicate that this fly-fungus interaction is not always a prerequisite for the initiation of the reproductive cycle of the fungus, as previously supposed (Rao \& Baumann, 2004; Rao et al., 2005; Górzyńska et al., 2010, 2011).

The fungus-insect interaction, which resembles the interaction between angiosperms and pollinating insects, raises the question of possible species specificity between flies and their fungal hosts. However, molecular studies have not confirmed the co-speciation of the fly and the fungal host (Leuchtmann, 2007). All the species of Botanophila collected in Europe are recorded from more than one species of Epichlö̈ and the most frequently recorded species are associated with as many as six fungal taxa. The only exception is the unidentified "Taxon 6", a putative species that is recorded from only two localities in the USA and associated with only one host, E. glyceriae. However, the lack of specialisation 
does not exclude that the flies show local preferences for specific hosts. This is documented for the Botanophila E. festucae system in Switzerland (Leuchtmann, 2007), where only one putative species of the fly (designated "Taxon 1") is recorded. These collections originated from four different localities in Switzerland. A similar situation is recorded for the stromata of E. baconii in Europe and of two North American species, E. elymi and E. glyceriae (the latter is based on few samples).

The preference of a particular species of Botanophila for a given species of fungus may result in two consequences. First, it may maximise the efficiency of fungal cross-fertilisation and thus ensure sufficient food for their developing larvae. Second, it may result in the prezygotic reproductive isolation between certain species of fungi that co-occur in a given area. For instance, crosses between the species E. typhina and E. clarkii may occur (Leuchtmann \& Schardl, 1998), although such hybrids have not been recorded in nature (Steinebrunner \& Leuchtmann, unpubl., after Bultman et al., 2011).

The aim of this study was to investigate the possible preferences and specificity of flies for the species of fungi they lay their eggs on and on which both their larvae and adults feed. For this we had to identify the flies collected from the different fungus-grass systems studied. However, currently there is no single method that can be used to identify the flies. Identification based on morphological traits is dependent on male flies being available, however, they are very difficult to collect in the field, and molecular identification does not provide unambiguous taxonomic results in the form of specific species names. Thus, we used both techniques and, in addition, checked the usefulness of morphological traits of eggs for identifying the species. A quick method for identifying the flies would greatly facilitate future studies on the ecology of this fly-fungus system.

\section{MATERIAL AND METHODS}

\section{Morphological identification of flies}

The only morphological characters that can currently be used to identify Botanophila phrenione and related species associated with the mycelium of Epichloë fungi are features of the terminalia of adult males. Unfortunately attempts to recover male flies from soil samples collected in the field that might have contained Botanophila puparia were unsuccessful. Similarly, we did not succeed in collecting any male specimens in the field. Hence, we investigated the differences in the surface structures of eggs and used these differences to make a preliminary distinction between the different fly taxa. A detailed SEM examination of the different egg morphotypes was conducted in the Electron and Confocal Microscope Laboratory at A. Mickiewicz University, Poznań, Poland. Subsequently, an attempt was made to assign these morphotypes to the taxa distinguished using a molecular method.

\section{Molecular identification of flies}

These analyses were conducted in June 2009 on fly larvae collected from the stromata of different species of Epichloë fungi infecting 7 species of grass in Poland (Table 1). Samples consisting of three larvae were collected using tweezers from each combination of grass-fungus at each locality. They were stored in $95 \%$ ethanol before DNA extraction. DNA was
TABLE 1. The association of the larvae of Botanophila with Epichloe fungi infecting particular species of grass, their geographic origin and identity of those species included in this study.

\begin{tabular}{|c|c|c|c|c|}
\hline $\begin{array}{c}\text { Fungal } \\
\text { host }\end{array}$ & Grass host & Site & Location & Fly species \\
\hline \multirow{6}{*}{ E. typhina } & \multirow{2}{*}{$\begin{array}{c}\text { Dactylis } \\
\text { glomerata }\end{array}$} & Morasko & $\begin{array}{l}52^{\circ} 27.857^{\prime} \mathrm{N} \\
16^{\circ} 55.868^{\prime} \mathrm{E}\end{array}$ & $\begin{array}{l}\text { B. phrenione } \\
\text { Taxon } 1\end{array}$ \\
\hline & & Pakość 1 & $\begin{array}{l}52^{\circ} 47.531^{\prime} \mathrm{N} \\
18^{\circ} 06.118^{\prime} \mathrm{E}\end{array}$ & B. phrenione \\
\hline & $\begin{array}{c}\text { Poa } \\
\text { trivialis }\end{array}$ & Rogalin & $\begin{array}{l}52^{\circ} 14.072^{\prime} \mathrm{N} \\
16^{\circ} 55.229^{\prime} \mathrm{E}\end{array}$ & B. phrenione \\
\hline & \multirow{3}{*}{$\begin{array}{c}\text { Puccinellia } \\
\text { distans }\end{array}$} & Janikowo & $\begin{array}{l}52^{\circ} 46.384^{\prime} \mathrm{N} \\
18^{\circ} 08.032^{\prime} \mathrm{E}\end{array}$ & B. phrenione \\
\hline & & Giebnia & $\begin{array}{l}52^{\circ} 46.544^{\prime} \mathrm{N} \\
18^{\circ} 06.190^{\prime} \mathrm{E}\end{array}$ & B. phrenione \\
\hline & & Pakość 2 & $\begin{array}{l}52^{\circ} 47.293^{\prime} \mathrm{N} \\
18^{\circ} 06.721^{\prime} \mathrm{E}\end{array}$ & $\begin{array}{l}\text { B. phrenione } \\
\text { Taxon } 1\end{array}$ \\
\hline \multirow{3}{*}{$\begin{array}{c}\text { E. } \\
\text { bromicola }\end{array}$} & \multirow{3}{*}{$\begin{array}{c}\text { Elymus } \\
\text { repens }\end{array}$} & Pakość 1 & $\begin{array}{l}52^{\circ} 47.397^{\prime} \mathrm{N} \\
18^{\circ} 06.064^{\prime} \mathrm{E}\end{array}$ & $\begin{array}{l}\text { B. lobata } \\
\text { Taxon } 1\end{array}$ \\
\hline & & Pakość 2 & $\begin{array}{l}52^{\circ} 47.325^{\prime} \mathrm{N} \\
18^{\circ} 06.824^{\prime} \mathrm{E}\end{array}$ & $\begin{array}{l}\text { B. lobata } \\
\text { Taxon } 1\end{array}$ \\
\hline & & Giebnia & $\begin{array}{l}52^{\circ} 46.556^{\prime} \mathrm{N} \\
18^{\circ} 06.977^{\prime} \mathrm{E}\end{array}$ & $\begin{array}{l}\text { B. lobata } \\
\text { Taxon } 1\end{array}$ \\
\hline E. clarkii & $\begin{array}{l}\text { Holcus } \\
\text { lanatus }\end{array}$ & Morasko & $\begin{array}{l}52^{\circ} 27.910^{\prime} \mathrm{N} \\
16^{\circ} 55.370^{\prime} \mathrm{E}\end{array}$ & B. phrenione \\
\hline E. festucae & $\begin{array}{c}\text { Festuca } \\
\text { rubra }\end{array}$ & Morasko & $\begin{array}{l}52^{\circ} 27.854^{\prime} \mathrm{N} \\
16^{\circ} 55.774^{\prime} \mathrm{E}\end{array}$ & Taxon 1 \\
\hline E. baconii & $\begin{array}{l}\text { Agrostis } \\
\text { alba }\end{array}$ & Pakość 2 & $\begin{array}{l}52^{\circ} 47.356^{\prime} \mathrm{N} \\
18^{\circ} 06.662^{\prime} \mathrm{E}\end{array}$ & Taxon 1 \\
\hline
\end{tabular}

extracted using the DNeasy Tissue Kit (Qiagen Inc., Valencia, CA, USA) and following the manufacturer's protocol. Next, the mitochondrial gene of subunit 2 of cytochrome c oxidase (COII) was amplified using a modification of primer TL2-J-3037 (5'TAATATGGCAGATTAGTGCA-3') and primer TD-N-3885 (Simon et al., 1994). These primers bind to the conserved regions of the genes (tRNA-Leu or tRNA-Asp, respectively) flanking the COII gene, and are expected to amplify an $860 \mathrm{bp}$ fragment. The PCR reaction was conducted in a $25 \mu 1$ volume containing $2.5 \mu \mathrm{l}$ of $10 \mathrm{X}$ buffer, $2.5 \mathrm{mM} \mathrm{MgCl} 2,0.1 \mathrm{mM}$ of each dNTP, $0.4 \mu \mathrm{M}$ of each primer, 1.25 U DNA Taq polymerase and $0.5-1 \mathrm{ng}$ template DNA. Amplification was conducted in a thermocycler (PTC-200, MJ Research) using a program with the following parameters: $7 \mathrm{~min} 94^{\circ} \mathrm{C} ; 45 \mathrm{~s} 94^{\circ} \mathrm{C}$, $45 \mathrm{~s} 50^{\circ} \mathrm{C}, 2 \min 70^{\circ} \mathrm{C} \times 25 ; 5 \min 70^{\circ} \mathrm{C}$. The products of the reaction were separated on a $1 \%$ agarose gel stained with ethidium bromide for confirmation. Sequencing reactions were then performed in $10 \mu 1$ volumes using BigDye Terminator v2.1 (Applied Biosystems, Foster City, CA, USA) and the products cleaned with a Purification Kit (Qiagen, Hilden, Germany), following the manufacturer's protocol, before obtaining the sequences using a 3130 Genetic Analyzer (Applied Biosystems). The sequences were edited and assembled using Sequencher 4.8 (Gene Codes Corp., Ann Arbor, MI, USA) and compared with aligned reference sequences of the six taxa of Botanophila distinguished by Leuchtmann (2007).

\section{Phylogenetic analysis}

The analysis of the 33 new sequences included three reference sequences and two out-group sequences (taken from a pre- 

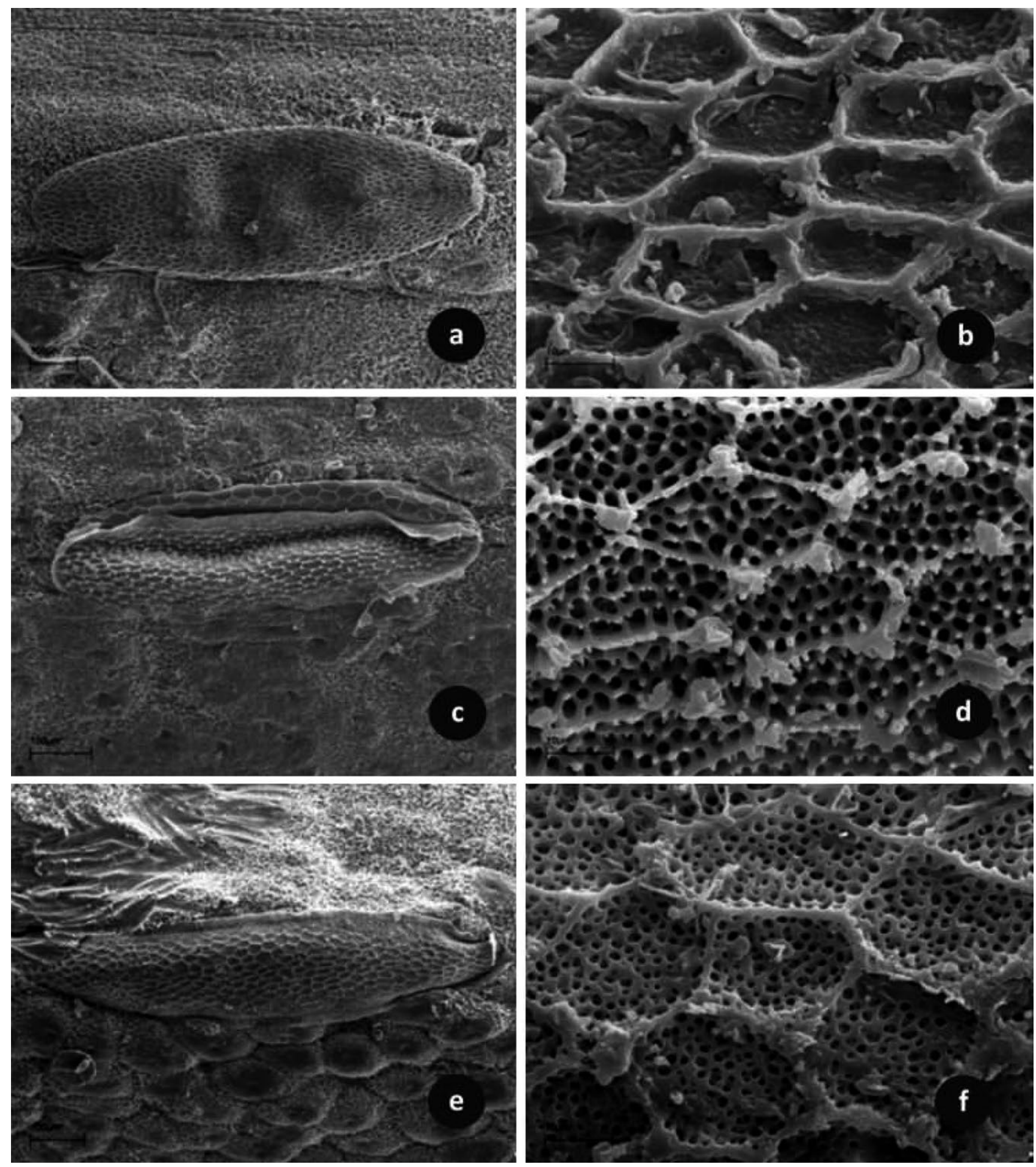

Fig. 1. Eggs of Botanophila flies collected from the stromata of Epichloë sp. infecting the grasses Dactylis glomerata (a, b, e, f) and Puccinellia distans (c, d): "grey eggs" (a, b), "cream eggs" (c, d), "white eggs" (e, f); (b, d, f) - magnified parts of the egg shells.

vious study, Leuchtmann, 2007). The maximum-likelihood (ML) tree was identified in PAUP* 4.0B10 using a general time-reversible (GTR) model and maximum likelihood settings from the best-fit model $(\operatorname{TrN}+\mathrm{G})$ selected by hierarchical likelihood ratio tests in MODELTEST 3.7 (Posada \& Crandall, 1998). The tree was inferred from 100 iterations with a random order of taxon addition and different values of the random number of seed. Confidence levels for the clades were assessed using ML bootstrap analysis (Efron \& Tibshirani, 1993) based on 100 heuristic replicates in PAUP.

\section{RESULTS}

\section{Morphological identification of eggs and their shells}

Three types of eggs were laid by female Botanophila on stromata of Epichloë fungi. They differed in shape, colour, presence or absence of dorsal folds and the sculpturing on the egg shells: (1) grey eggs (Fig. 1a, b), "slender", without dorsal folds, the shell surface with a reticulated polygonal pattern with no pits within the poly- 


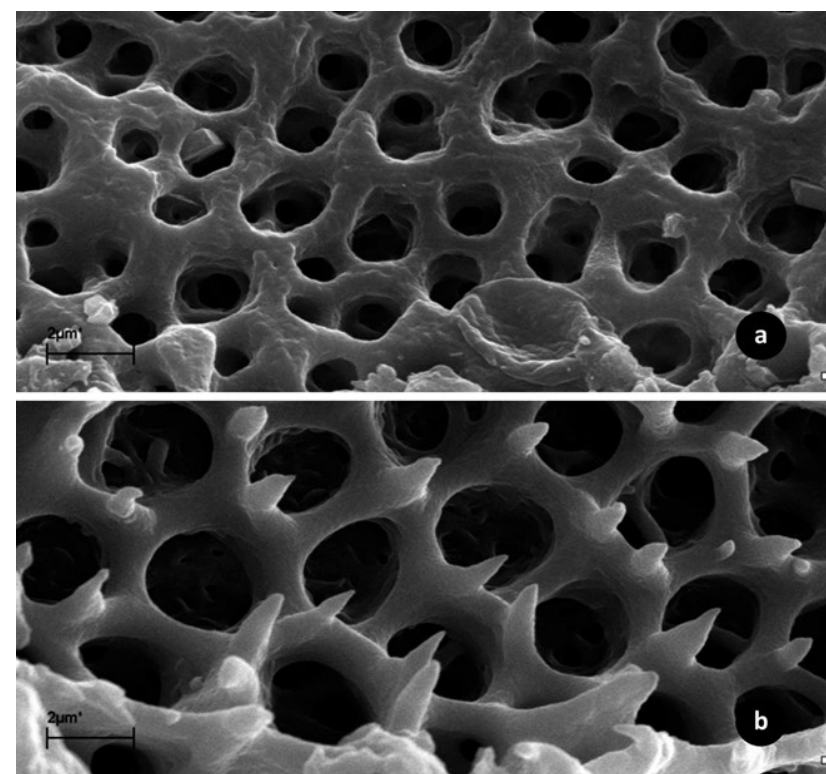

Fig. 2. Magnified parts of the egg shells of Botanophila spp. collected from the stromata of Epichloë typhina infecting Dactylis glomerata. There are marked differences in the structure with an absence of projections on some (a) and numerous distinct projections on others (b)

gons; (2) cream coloured eggs (Figs 1c, d, 2), with a double dorsal fold, the shell surface with a reticulated polygonal pattern with numerous pits and distinct spikelike projections between the pits; and (3) pure white eggs (Figs 1e, f, 2), bulky, with a double dorsal fold and the shell surface with a reticulated polygonal pattern and numerous pits, but no spike-like projections between pits. These differences in the egg shells were not correlated with the species of fungus.

\section{Molecular identification and phylogenetic relationships}

COII sequences of the 33 fly larvae collected from the stromata of different species of Epichloë formed three distinct clades (Fig. 3). Each clade was closely associated with the reference sequence of one of three Botanophila taxa. Eighteen larvae grouped with $B$. phrenione, five with $B$. lobata and 10 with unidentified "Taxon 1". No species name could be assigned to this taxon, because the absence of adult male specimens made it impossible to identify this species. Although there was some genetic variability among sequences assigned to particular taxa, clades were well-separated and had $97-100 \%$ bootstrap support.

\section{Fly preferences}

Only one of the three fly taxa, identified as B. lobata, was restricted to a single species of Epichloë (E. bromicola on Elymus repens) (Table 1). This species of Botanophila was recorded at all three localities at which this association occurred. In each case, however, $B$. lobata was accompanied by another fly taxon, denoted "Taxon 1". The second species, B. phrenione, was recorded mainly from E. typhina infecting three different grass species (Table 1) but also from the stromata of $E$.

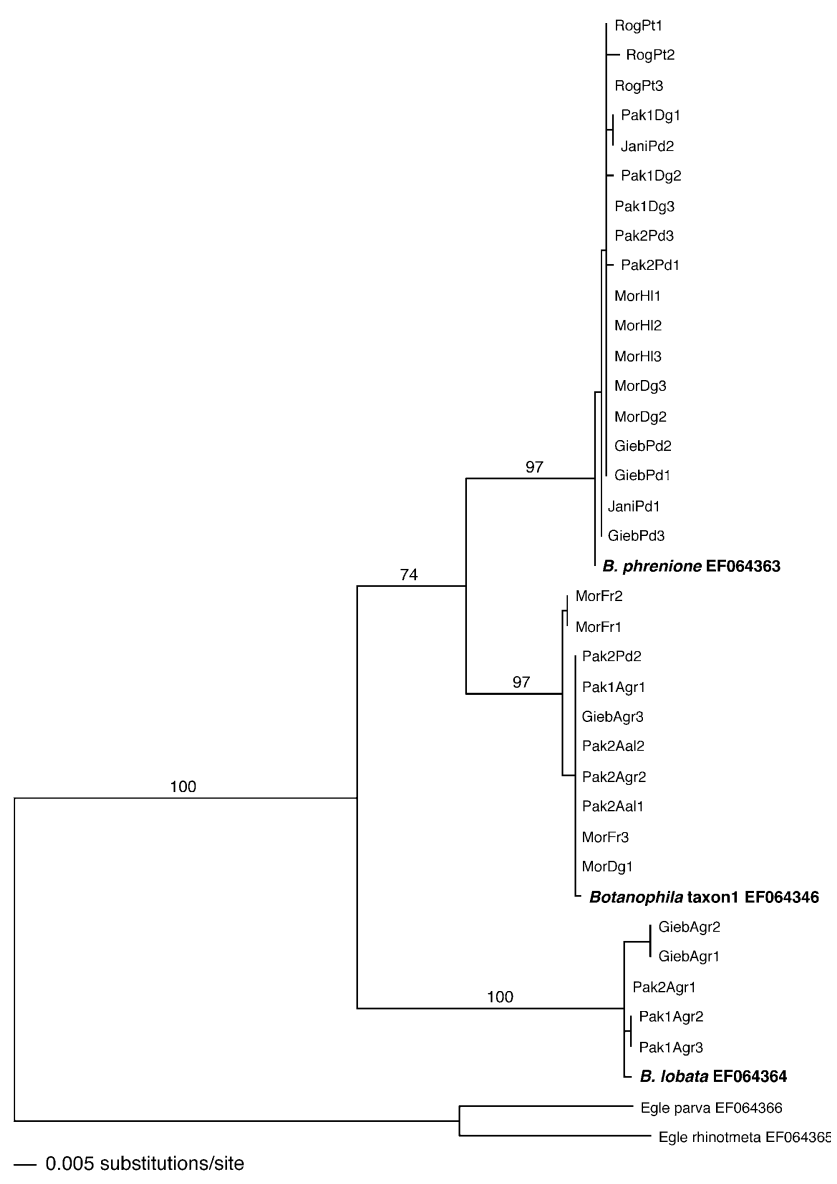

Fig. 3. Maximum-likelihood tree for Botanophila based on sequences of the subunit 2 of mitochondrial cytochrome oxidase (COII) that were obtained from larvae collected from different Epichloë fungi in Poland. Three reference sequences of previously identified Botanophila taxa (Leuchtmann, 2007), with their GenBank accession numbers, are included. ML bootstrap percentages are indicated above the supporting branches. The phylogram is rooted in two outgroup species of the genus Egle.

clarkii infecting Holcus lanatus. For the latter, it was the only fly taxon recorded from this species of Epichloë. The third fly taxon, "Taxon 1", was the most frequent. It was recorded from all the fungal species studied except the stromata of E. clarkii on H. lanatus (Table 1). Only on two species of fungi, E. clarkii and E. festucae, were the larvae of a single taxon recorded (B. phrenione and "Taxon 1", respectively).

\section{DISCUSSION}

The molecular techniques used in this study revealed that there are three different taxa of flies, belonging to the genus Botanophila, in Poland. One of them is B. phrenione, a species recorded before from two grasses, Dactylis glomerata and Puccinellia distans, infected with the fungus Epichloë typhina (Gorzyńska et al., 2010, 2011). The second is B. lobata, which is a new record for Poland. The third denoted "Taxon 1", remains unidentified because of the absence of adult male specimens. However, based on the characteristics of its association with a particular host fungus, it is considered to be a new species for Poland. These three taxa of Botanophila have 
not yet been listed in taxonomic and faunistic works that include Poland (Komzáková \& Rozkošný, 2009; Michelsen, 2011).

The results of our studies confirm the hypothesis that there is not a close species specific association between fungi and this insect (Leuchtmann, 2007). Of the three fly taxa recorded in Poland only B. lobata was recorded from a single fungal species, Epichloë bromicola infecting Elymus repens. This species of Botanophila was observed at all the localities where E. bromicola was present. The other two taxa, B. phrenione and "Taxon 1", do not have a specific association with a particular species of fungus. A previous study (Leuchtmann, 2007) records that all the European taxa are associated with more than one species of Epichloë and the most frequent taxon, the unidentified "Taxon 1", is recorded from as many as six species. The only exception is a taxon designated "Taxon 6", recorded at two localities in the USA, which is associated with just one fungal species, E. glyceriae.

The analysis of the associations of the different taxa of flies with particular species of grass infected with these fungi, revealed certain differences not recorded by Leuchtmann (2007). First, regarding the E. typhina - P. distans interaction, there are two fly taxa (B. phrenione and "Taxon 1"), not just one ("Taxon 1"). This is possibly due to sample size. In this study eight samples were collected from three localities, while Leuchtmann (2007) analyzed only one sample, which originated from Giebnia in Poland. Second, B. lobata was recorded in Poland only from the stromata of E. bromicola, whereas this species is recorded by Leuchtmann (2007) as being associated with the interaction E. typhina - D. glomerata in Switzerland and with E. festucae - F. rubra in the USA. In addition, this author records $B$. lobata from stromata on three other host grasses not included in the present study. A probable reason for this discrepancy, besides the limited number of samples examined, may be the local preference of $B$. lobata for E. bromicola rather than E. typhina or E. festucae in Poland. Previous studies also suggest that certain species of this fly visit one host more frequently than other hosts (Bultman \& Leuchtmann, 2003; Bultman et al., 2011).

B. phrenione occurs in the Western Palaearctic (Komzáková \& Rozkošný, 2009). This species was recorded by Leuchtmann (2007) only from grass - fungus systems in Europe (from E. clarkii, E. sylvatica and E. typhina infecting six different species of grass). In contrast, B. lobata occurs in Eurasia, but previously noted only in Europe and Japan (Collin, 1967; Suwa, 1999). In Europe, this species is most commonly recorded from $E$. bromicola infecting E. repens (this study) and Bromus erectus, and from E. sylvatica infecting Brachypodium sylvaticum and is only recorded once from E. typhina infecting $D$. glomerata (Leuchtmann, 2007). In the USA, however, larvae of $B$. lobata are frequently recorded from the stromata of the introduced $E$. typhina infecting $D$. glomerata and $E$. festucae infecting $F$. rubra. Presumably, B. lobata is not a native of the USA but was brought to the USA with the fungus (Rao et al., 2005).
The absence of natural enemies (e.g., parasitoids) may have facilitated the acclimatisation of this taxon, which is the most frequently recorded representative of the Epichloë-associated Botanophila species in the USA (Rao \& Baumann, 2004; Rao et al., 2005). Two additional putative species ("Taxon 5" and "Taxon 6") distinguished by Leuchtmann (2007) are only found in the USA and not so far recorded in Poland.

Among the six Botanophila taxa previously identified from Epichloë hosts by Leuchtmann (2007), three are European and two North American. One taxon occurs on both continents. However, the phylogeny of these taxa does not reflect their geographic origin. B. phrenione and "Taxon 1" form a common clade with the American "Taxon 5", whereas B. lobata is more distantly related to this group. B. phrenione, B. lobata and "Taxon 1" recorded in Poland are also common in Switzerland (Leuchtmann, 2007). This result suggests that two confirmed and one putative species are widely distributed in continental Europe. The fourth putative species, denoted "Taxon 4", is rare in Switzerland and not found in Poland.

Determination of distribution ranges of fly taxa and occurrence in individual grass-fungus systems is hindered by the difficulties in species identification. Usually, only larvae or female flies are available, which are difficult to identify. All current techniques have shortcomings. The use of molecular methods to identify species depends on the availability of reference sequences for each of the species. This is the case for $B$. phrenione and B. lobata, for which there are $C O I I$ sequences for males of these species collected in the field (Leuchtmann, 2007). The third species (denoted "Taxon 1") is designated putative, because this species has not been confirmed. Since COII genes are maternally inherited and no other nuclear genes were analyzed, it is not possible to exclude the false interpretation of the clade denoted "Taxon 1". However, all the COII sequences of larvae of "Taxon 1" from nine different sites in Switzerland (Leuchtmann, 2007) and four in Poland (this study) form a distinct and uniform clade that is wellseparated from B. phrenione and B. lobata. Furthermore, in the taxonomic literature there are at least six Botanophila species associated with Epichloë fungi in Europe (Collin, 1967; Ackland, 1972; Hennig, 1976) and it is likely that "Taxon 1" is one of them.

The molecular analysis needs to be associated with specific morphological identifications. However, the adult males required for identification are not recorded from fungal stromata and are difficult to find in the nearby vegetation. Therefore, attempts were made to distinguish fly taxa based on egg morphology. Scanning electron microscopy of the shells of eggs revealed that there are three morphologically distinct types of eggs, which differ in shape, colour, presence or absence of dorsal folds and sculpturing of the surface (Figs 1,2). It is likely that these differences will be used in the future for identifying these flies. Tentatively, the three colours of eggs are associated with the following species of flies: "grey" $B$. laterella, "white" B. phrenione and B. dissecta and "cream" $B$. 
lobata. However, the different eggs have yet to be associated with particular species of Botanophila based on molecular identification. As the "grey" eggs did not hatch it was not possible to use molecular sequences to identify them. Larvae referred to as "Taxon 1" most likely represent $B$. dissecta, because all the larvae assigned to "Taxon 1 " based on molecular sequences hatched from "white" eggs. Results and observations on egg morphology will be used in the future to identify the flies associated with particular species of Epichloë.

ACKNOWLEDGEMENTS. We thank B. Blattmann for laboratory assistance. The work was supported by grant NN 303321 237 from the Polish Ministry of Science and Higher Education. We thank anonymous reviewers for their helpful comments.

\section{REFERENCES}

ACKLAND D.M. 1972: A further note on anthomyiid flies associated with Epichloë fungus. - The Entomologist 105: 231-232.

Brem D. \& Leuchtmann A. 1999: High prevalence of horizontal transmission of the fungal endophyte Epichloë sylvatica. Bull. Geobotan. Inst. ETH 65: 3-12.

Bultman T.L. 1995: Mutualistic and parasitic interactions between Phorbia flies and Epichloë: convergence between a fungus and entomophilous angiosperms. - Can. J. Bot. 73: 1343-1348.

Bultman T.L. \& Leuchtmann A. 2003: A test of host specialization by insect vectors as a mechanism for reproductive isolation among entomophilous fungal species. - Oikos 103: 681-687.

Bultman T.L., Leuchtmann A., Sullivan T.J. \& Dreyer A.P. 2011: Do Botanophila flies provide reproductive isolation between two species of Epichloë fungi? A field test. - New Phytol. 190: 206-212.

Chung K.R. \& Schardl C.L. 1997: Sexual cycle and horizontal transmission of the grass symbiont, Epichloë typhina. Mycol. Res. 101: 295-301.

Collin J.E. 1967: Notes on some British species of Pegohylemyia (Dipt., Anthomyiidae) with descriptions of four new species. - Entomol. Mon. Mag. 102: 181-191.

Efron B. \& Tibshirani R. 1993: An Introduction to the Bootstrap. Chapman \& Hall/CRC, Boca Raton, FL, 456 pp.

Górzyńska K., Lembicz M., Olszanowski Z. \& Leuchtmann A. 2010: An unusual Botanophila-Epichloë association in a population of orchardgrass (Dactylis glomerata) in Poland. J. Nat. Hist. 44: 2817-2824.

Górzyńska K., Lembicz M., Olszanowski Z. \& Leuchtmann A. 2011: Botanophila-Epichloë interaction in a wild grass, Puccinellia distans, lacks dependence on the fly vector. - Ann. Entomol. Soc. Am. 104: 841-846.

HenNIG W. 1966-1976: Anthomyiidae. In Lindner E. (ed.): Die Fliegen der palaearktischen Region, Vol. 7(1). Schweizerbart, Stuttgart, pp. 1-974.

Kohlmeyer J. 1956: Über Verbreitung und Biologie von Phorbia (Pegohylemyia) phrenione (Séguy 1937). - Beitr. Entomol. 6: 659-670.

KomzÁKovÁ O. \& RozkošNÝ R. 2009: Identification of central European species of Botanophila Lioy, 1864, based on the female terminalia (Diptera: Anthomyiidae). - Acta Zool. Acad. Sci. Hung. 55: 321-337.

Leuchtmann A. 2007: Botanophila flies on Epichloë host species in Europe and North America: no evidence for coevolution. - Entomol. Exp. Appl. 123: 13-23.

Leuchtmann A. \& Scharde C.L. 1998: Mating compatibility and phylogenic relationships among two species of Epichloë and other congerenic European species - Mycol. Res. 102: $1169-1182$.

Michelsen V. 2011: Fauna Europaea: Anthomyiidae. In Pape T. \& Beuk P. (eds): Fauna Europaea: Diptera, Brachycera. Fauna Europaea version 2.4, http://wwwfaunaeur.org

Posada D. \& Crandall K.A. 1998: Modeltest: testing the model of DNA substitution. - Bioinformatics 14: 817-818.

Rao S. \& Baumann D. 2004: The interaction of Botanophila fly species with an exotic Epichloë fungus in a cultivated grass: fungivore or mutualist? - Entomol. Exp. Appl. 112: 99-105.

Rao S., Alderman S.C., Takeyasu J. \& Matson B. 2005: The Botanophila-Epichloë association in cultivated Festuca in Oregon: evidence of simple fungivory. - Entomol. Exp. Appl. 115: 427-433.

Simon C., Frati F., Beckenbach A., Crespi B., Liu H. \& Flook P. 1994: Evolution, weighting, and phylogenetic utility of mitochondrial gene sequences and a compilation of conserved polymerase chain reaction primers. - Ann. Entomol. Soc. Am. 87: 651-701.

Suwa M. 1999: Japanese records of anthomyiid flies. - Insecta Matsumur. N.S. 55: 203-244.

WiLLiams C.B. 1971: Notes on a fungus-eating anthomyid fly in North Britain and North America. - The Entomologist 104: $1-3$.

Received April 10, 2012; revised and accepted August 17, 2012 